\title{
Fluorination of organoboron compounds
}

\author{
Graham Pattison*a
}

Received 00th January 20xx, Accepted 00th January 20xx

DOI: $10.1039 / \times 0 \times x 00000 x$
Methods for the fluorination of organoboron compounds are described. This review will cover the fluorination of aromatic and aliphatic systems using both electrophilic and nucleophilc sources of fluorine. Emerging methods for radiofluorination using ${ }^{18} \mathrm{~F}$ for the synthesis of PET-imaging agents are also described.

\section{Introduction}

Fluorinated organic compounds have emerged as some of the most important compounds in modern pharmaceutical and agrochemical discovery. ${ }^{1}$ Over $25 \%$ of all drugs on the market today contain a fluorine atom and the figure is even higher for agrochemicals. Fluorine is able to modulate a range of factors which can affect the activity, efficacy and availability of bioactive molecules, including their lipophilicity, acidity and polarity. In addition, the high strength of the $\mathrm{C}-\mathrm{F}$ bond means that fluorine is often introduced into target molecules as an unreactive group designed to block unwanted metabolic reactions. ${ }^{2}$

Chemists involved in the design and synthesis of such bioactive agents therefore desire simple and efficient methods for the introduction of fluorine atoms into organic molecules. Of these methods, those which allow the transformation of stable, easily-handled and readily-introduced precursor functional groups into fluorine atoms are particularly desirable.

Boron-containing compounds present a commonlyoccurring example of a stable, readily-synthesized and convenient functional handle for the construction of new carbon-carbon and carbon-heteroatom bonds. ${ }^{3}$ Boron has proved hugely influential in the development of metalcatalyzed cross-coupling reactions (e.g. Suzuki-Miyaura coupling, Chan-Lam coupling), ${ }^{4}$ conjugate addition reactions, ${ }^{5}$ stereospecific homologation processes, ${ }^{6}$ and hydroboration reactions, ${ }^{7}$ to name just a few key examples. However, until the last few years, examples of $\mathrm{C}-\mathrm{F}$ bond formation from organoboron precursors have proven extremely rare. This situation is beginning to change, particularly through the development of modern metal-mediated fluorination processes.

\footnotetext{
a. Chemistry Research Group, School of Pharmacy and Biomolecular Sciences,
} University of Brighton, Brighton, BN2 4GJ, UK. Email: g.pattison@brighton.ac.uk
Alternatives to the fluorination of organoboron compounds include the fluorination of organohalides $^{8}$ and $\mathrm{C}-\mathrm{H}$ fluorination. ${ }^{9}$ The robustness of organoboron precursors mean that they are much less susceptible towards side reactions such as elimination or radical processes than organohalides, whilst still offering a functional handle that gives regiochemical control that may be challenging to achieve in $\mathrm{C}-\mathrm{H}$ fluorination.

This review will describe how the fluorination of organoboron compounds has developed, with a particular emphasis on recent developments. For convenience, the review shall be divided to discuss fluorination of aromatic and aliphatic organoboron systems separately, and the emerging area of radiochemical fluorination using ${ }^{18} \mathrm{~F}$ will also be discussed.

\section{Aromatic Fluorination}

Many successful pharmaceuticals contain an aromatic ring bearing a single fluorine atom (Figure 1). Whilst traditionally these might have been synthesized using the Balz-Schiemann fluorination of diazonium salts, chemists now urgently desire

Dr. Graham Pattison is currently Lecturer in Organic Chemistry at the University of Brighton. He studied for a MChem degree in Chemistry at Durham University and a PhD in heterocyclic organofluorine chemistry at the same institution under the supervision of Prof. Graham Sandford. He moved to the University of Edinburgh for a postdoctoral position with Prof. Hon Wai Lam, before joining the University of Warwick for an independent research fellowship position. He moved to Brighton in 2018, where his research interests are in organofluorine chemistry, organoboron chemistry and in catalysis.

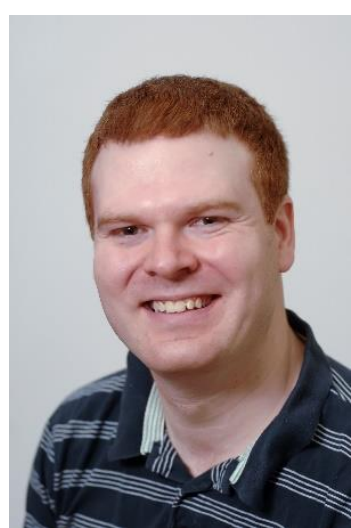




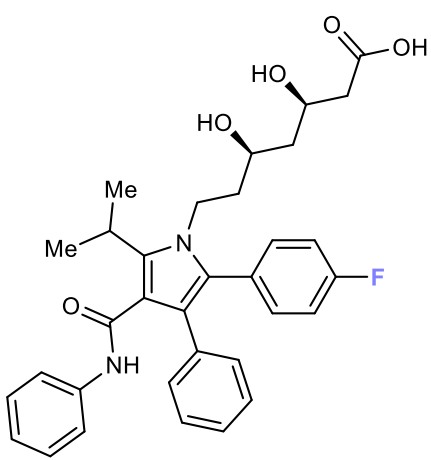

Atorvastatin (Lowers cholesterol)<smiles>CNCCC[C@]1(c2ccc(F)cc2)OCc2cc(C#N)ccc21</smiles>

Escitalopram (Antidepressant)

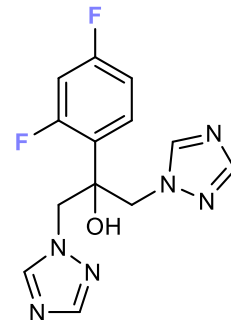

Fluconazole (Antifungal)<smiles>O=C(O)c1cn(C2CC2)c2cc(N3CCNCC3)c(F)cc2c1=O</smiles>

Ciprofloxacin (Antibiotic)

Figure 1: Selected pharmaceutical products containing an aromatic $\mathrm{C}-\mathrm{F}$ bond

new protocols which utilize safer precursors and milder conditions. The widespread commercial availability of aromatic organoboron compounds, as well as the many convenient methods for their synthesis, which has been driven by the widespread application of catalytic couplings such as the SuzukiMiyaura reaction, means that these stable and easily-handled precursors would make ideal substrates for $\mathrm{C}-\mathrm{F}$ bond formation.

\subsection{Metal-Free Fluorination}

Early efforts for the fluorination of aromatic organoboron compounds focussed on the use of highly reactive fluorinating agents. Widdowson and co-workers showed that cesium fluoroxysulfate could promote the ipso-fluorination of certain aromatic organoboronic acids (Scheme 1A). ${ }^{10}$ Yields were generally moderate (generally $20-50 \%$ ), but could be enhanced by using methanol as solvent, possibly through the formation of methyl boronic esters. In certain cases, particularly when using electron-rich aromatic rings bearing groups such as alkoxygroups, additional fluorinated isomers formed through orthodirected electrophilic aromatic substitution were also observed. Whilst pinacol and ethylene glycol boronic esters showed no reactivity, esters prepared from $\mathrm{N}$-methyl-diethanolamine did give ipso-fluorination in $15-52 \%$ yield. However, as cesium fluoroxysulfate can undergo explosive decomposition in the presence of metals or under pressure, its usage is not to be advised. ${ }^{11}$

More recently, Rozen has shown that acetyl hypofluorite can promote the ipso-fluorination of aromatic boronic acids and pinacol esters in synthetically useful yields (Scheme 1B). ${ }^{12}$ Again

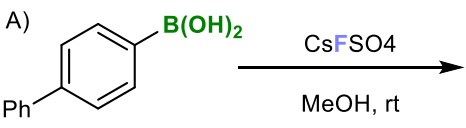<smiles>Fc1ccc(-c2ccccc2)cc1</smiles>

B)<smiles>[R]c1ccc(F)cc1</smiles>

$2 \mathbf{a}$

$85 \%$

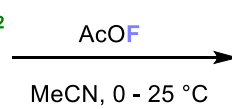

$10-30 \mathrm{~min}$<smiles>CC(C)(C)c1ccc(F)cc1</smiles>

2b $\mathrm{BrH}_{2} \mathrm{C}$<smiles>[R]c1ccc(F)cc1</smiles>

2<smiles>Fc1ccc(CBr)cc1</smiles>

2c

$80 \%$<smiles>O=[N+]([O-])c1ccc(F)cc1</smiles>

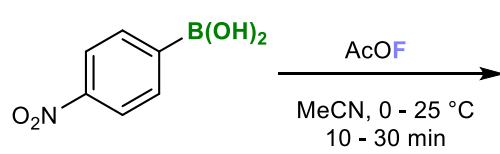

2d<smiles>O=[N+]([O-])c1cccc(F)c1</smiles>

2d'

$32 \%$

Scheme 1: Metal- free ipso-fluorination of boronic acids

in certain examples, boron was observed to direct electrophilic ortho $\mathrm{C}-\mathrm{H}$ bond fluorination leading to the formation of fluorinated regioisomers $\mathbf{2} \mathbf{d} / \mathbf{2} \mathbf{d}^{\prime}$, particularly in cases where an electron-withdrawing group was para- to boron. This selectivity is in agreement with recent physical-organic studies by Mayr on the reactivity of aryl trifluoroborates in electrophilic aromatic substitution reactions. ${ }^{13}$ Again the use of acetyl hypofluorite presents several concerns, as it must be prepared in-situ by reaction of diluted elemental fluorine with sodium acetate requiring specialist skills and equipment, and concentrated solutions of this reagent have been reported to be explosive. ${ }^{14}$

Lemaire has reported that reaction of some electron-rich aromatic and bicyclic naphthalene-based boronic acids and trifluoroborates undergo successful fluorination with Selecfluor in acetonitrile. ${ }^{15}$ Although this is an attractive reaction, the reported scope is limited, and in several cases fluorinated products were contaminated with significant amounts of protodeboronated material.

\subsection{Metal-mediated / catalyzed fluorination}

The majority of the synthetically practical fluorination procedures that have emerged for aromatic organoboron compounds rely on the use of a transition metal reagent or catalyst to mediate the fluorination. In general, these reactions use fluorinating agents that are more easily handled, including electrophilic $\mathrm{N}-\mathrm{F}$ reagents such as Selectfluor and NFSI, as well 

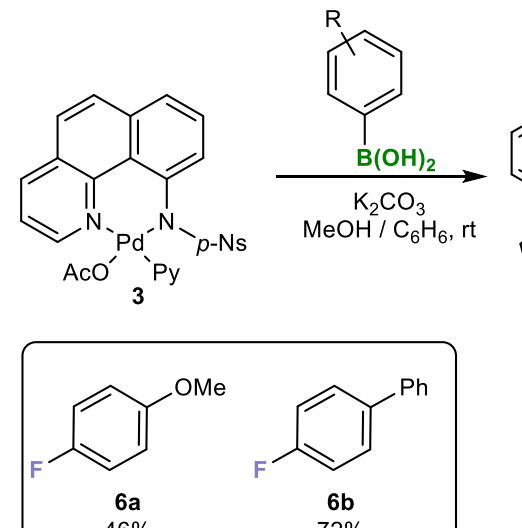

$46 \%$

$72 \%$
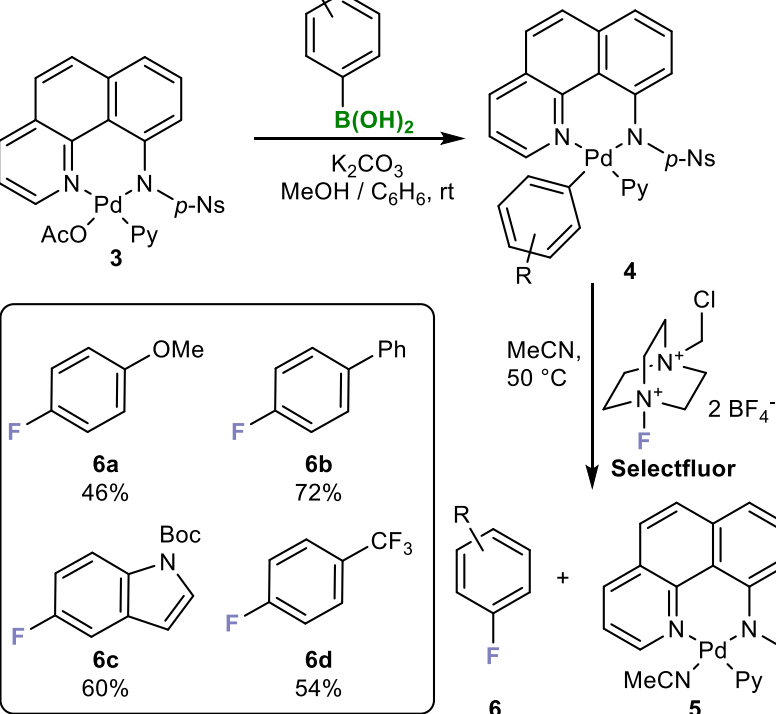

Scheme 2: Fluorination of $\mathrm{Pd}(\mathrm{II})$-aryl complexes formed from boronic acids (Yields are based on the step $\mathbf{4}$ to $\mathbf{6}$ )

as fluoride sources. A recurring theme in these reactions is the formation of high oxidation states of transition metals, promoted by the oxidizing power of electrophilic sources of fluorine. The majority of these reactions have been promoted by either palladium, silver or copper, and these shall each be discussed in turn.

\subsubsection{Palladium-mediated / catalyzed fluorination}

A key breakthrough in aromatic fluorination was made between 2006 and 2008 by Sanford and Ritter, who recognized that palladium complexes in high oxidation states such as $\mathrm{Pd}(\mathrm{III})$ and $\mathrm{Pd}(\mathrm{IV})$ were able to promote the reductive elimination of $\mathrm{C}-\mathrm{F}$ bonds. Whilst Sanford focussed her work mainly on directed $\mathrm{C}-\mathrm{H}$ bond fluorination, ${ }^{16}$ Ritter developed systems appropriate for the fluorination of aromatic boronic acids.

Ritter's initial approach used stoichiometric formation of palladium(II)-aryl complexes, formed by the transmetallation of a Pd(II) complex 3 with arylboronic acids (Scheme 2). ${ }^{17}$ These $\mathrm{Pd}(\mathrm{II})$-aryl species 4 then underwent reaction with Selectfluor at $50{ }^{\circ} \mathrm{C}$ to yield aryl fluorides 6 . This approach was compatible with a broad range of boronic acids, including electron-rich, electron-poor and heterocyclic examples, and the reaction was not sensitive to air and moisture. Several Pd-complexes were characterized by X-ray crystallography, and it was proposed that this reaction proceeded via a high oxidation state of palladium, most likely $\mathrm{Pd}(\mathrm{IV})$. Although this was not observed directly in this case, several such $\operatorname{Pd}(\mathrm{IV})$-fluoride complexes have been shown to be competent in $\mathrm{C}-\mathrm{F}$ bond reductive elimination, and can be accessed by reaction of $\mathrm{Pd}(\mathrm{II})$-aryl species with Selectfluor. ${ }^{18}$

More recently, Ritter has developed a fluorination of aryl trifluoroborate salts which is catalytic in palladium and which proceeds by a different mechanism (Scheme 3 ). ${ }^{19}$ This reaction used a $\mathrm{Pd}$ (terpyridyl) complex 7 , but does not yield $\mathrm{C}-\mathrm{F}$ bonds through the formation of a palladium-aryl species. Instead, single-electron transfer from Pd(II)-complex 7 to Selectfluor

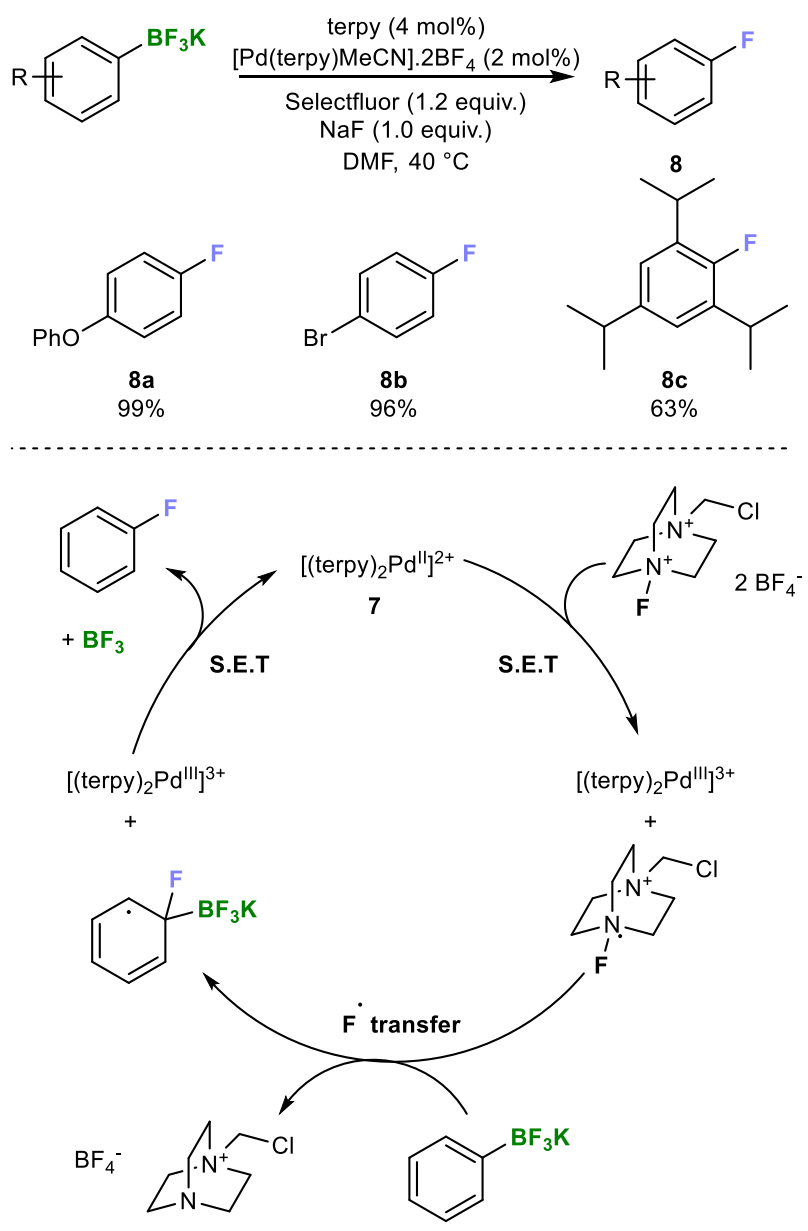

Scheme 3: Pd(II)-catalyzed fluorination of aryl trifluoroborates

yields a $\mathrm{Pd}(\mathrm{III})$ complex and Selectfluor radical cation. This radical cation is then able to transfer a fluorine atom to an aryl trifluoroborate, yielding a dearomatized species which forms an aryl fluoride with loss of $\mathrm{BF}_{3}$ and simultaneous reduction of $\mathrm{Pd}(\mathrm{III})$ to $\mathrm{Pd}(\mathrm{II})$. This alternative mechanism means a wide range of substrates can undergo fluorination, with electron-rich boronic acids being most effective. In general protodeboronation, which sometimes proved problematic when using Pd-aryl complexes, was not an issue in this reaction. Aryl trifluoroborates could be formed in-situ from either boronic acids or esters and a mixture of $\mathrm{NaF}$ and $\mathrm{KHF}_{2}$, and aryl MIDA- boronates also showed reactivity, albeit less than aryl trifluoroborates. Again, this reaction can be performed in an open flask under highly practical conditions.

\subsubsection{Ag-mediated fluorination}

The Ritter group have also shown that silver(I) (in the form of AgOTf) is a viable metal to mediate the fluorination of aromatic boronic acids (Scheme 4). ${ }^{20}$ This fluorination proceeded with broad scope, and included a range of electronically diverse, sterically hindered and heterocyclic boronic acids. The reaction could easily be performed on a gram-scale. Aryl pinacol esters also participated in this fluorination, although yields were slightly reduced compared to boronic acids. This reaction used 


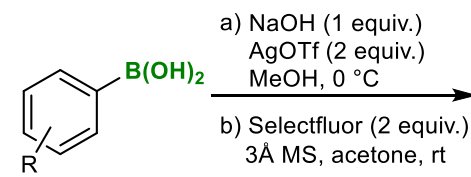<smiles>Fc1ccccc1</smiles>

9<smiles>Fc1ccc(F)cc1</smiles><smiles>CC(C)(C)c1ccc(F)cc1</smiles><smiles>Fc1ccc2nccnc2c1</smiles>

$9 a$

$85 \%$
$9 b$
$9 \mathrm{c}$

$71 \%$

Scheme 4: Ag-mediated fluorination of boronic acids<smiles>Brc1cc[R]cc1</smiles>

[ $\left.\mathrm{Me}_{3} \mathrm{pyF}\right] \mathrm{PF}_{6}$ (3 equiv.)

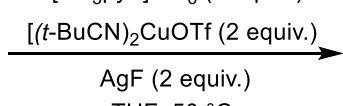
$\mathrm{THF}, 50^{\circ} \mathrm{C}$

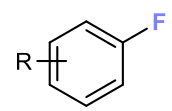

10<smiles>Fc1ccc(-c2ccccc2)cc1</smiles><smiles>CC(=O)c1cccc(F)c1</smiles><smiles>C[C@]12CC[C@H]3c4ccc(F)cc4CC[C@]3(C)[C@@H]1CCC2=O</smiles>

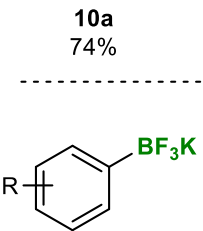

$10 \mathrm{~b}$

[ $\mathrm{Me}_{3}$ pyF] OTf (2 equiv.)

$\underset{\left[(t-\mathrm{BuCN})_{2} \mathrm{CuOTf}(2 \text { equiv. })\right.}{\longrightarrow}$<smiles>Fc1ccccc1</smiles>

11<smiles>Cc1cc(C)c(F)c([N+](=O)[O-])c1</smiles><smiles>Fc1ccc(C(F)(F)F)cc1</smiles><smiles>CC(=O)c1ccc(F)cc1</smiles>

$74 \%$

$54 \%$

2 equivalents of AgOTf to mediate the fluorination process, and it was hypothesised that a bimetallic $\mathrm{Ag}(\mathrm{II})$-intermediate may be important for reactivity, as it was shown to be in a related $\mathrm{Ag}$ mediated fluorination of aryl stannanes. ${ }^{21}$

\subsubsection{Cu-mediated Fluorination}

Copper is emerging as one of the most versatile metals to promote aromatic fluorination. In 2013 Hartwig $^{22}$ and Sanford ${ }^{23}$ independently published related fluorination reactions of arylboronate esters and aryl trifluoroborates respectively (Scheme 5$)$. Both reactions were mediated by $(t-\mathrm{BuCN})_{2} \mathrm{CuOTf}$ and used an $\mathrm{N}$-fluoropyridinium salt as an electrophilic source of fluorine. These proceeded under mild conditions and tolerated a wide range of functionality. Hartwig also showed that Ir-catalyzed $\mathrm{C}-\mathrm{H}$ borylation and $\mathrm{Cu}$-mediated fluorination could be performed in a sequential manner to yield a net $\mathrm{C}-\mathrm{H}$ fluorination. Hartwig performed detailed mechanistic work which suggested that this reaction proceeded through a $\mathrm{Cu}(\mathrm{III})$ fluoride species.

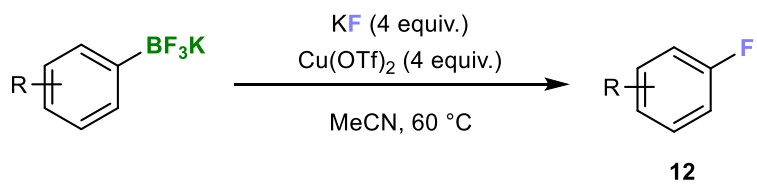<smiles>Cc1ccccc1F</smiles><smiles>Fc1ccc(OC(F)(F)F)cc1</smiles><smiles>Fc1ccc2c(c1)oc1ccccc12</smiles>

$12 a$ $48 \%$ 12b $71 \%$ $12 c$
$67 \%$

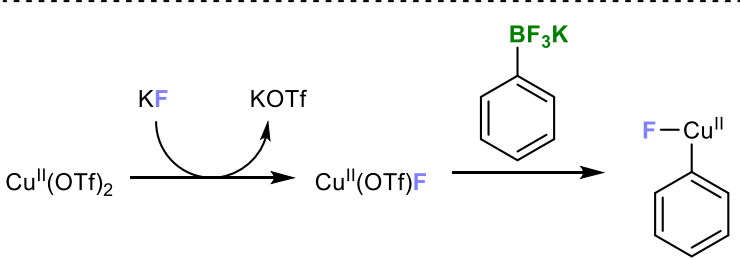<smiles>Cc1ccccc1F</smiles><smiles>[O-][C-](F)c1ccccc1</smiles>

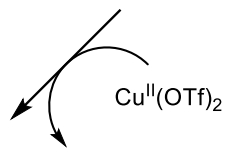

$\mathrm{Cu}^{\prime}(\mathrm{OTf})$

An important development in this area was then made later in 2013 by Sanford's group. ${ }^{24} \mathrm{Cu}(\mathrm{OTf})_{2}$ was used to mediate the fluorination of aryl trifluoroborates using a nucleophilic source of fluorine (Scheme 6). This reaction used KF as fluoride source and was the first example of fluorination of an organoboron compound using a cheap and readily available source of nucleophilic fluoride. Yields were generally good, and aryl pinacolboronates were also fluorinated under these conditions in moderate yields. In addition, amounts of competing protodeboronated products were reduced in this reaction compared to the earlier Cu-mediated reactions using electrophilic sources of fluorine. As excess $\mathrm{Cu}(\mathrm{OTf})_{2}$ (4 equivalents) is required for this reaction, it has been proposed that a second equivalent of $\mathrm{Cu}(\mathrm{OTf})_{2}$ is required to oxidize a $\mathrm{Cu}$ (II) intermediate to $\mathrm{Cu}$ (III) in a net disproportionation reaction.

\subsubsection{Other Metals}

Dubbaka has reported an $\mathrm{FeCl}_{3}$ / Selectfluor-mediated fluorination of aryl trifluoroborates. ${ }^{25}$ However in many cases this procedure led to the formation of ortho- as well as ipsosubstituted regioisomeric products, particularly in the cases of electron-rich aromatic rings. These regioisomers were particularly prevalent with a strong electron-donating group 
para- or meta- to boron. This is a similar result to that observed in metal-free fluorination protocols of aryl boron species.

Pinhey and De Meio developed an interesting fluorination of triarylboroxines using $\mathrm{BF}_{3} \cdot \mathrm{Et}_{2} \mathrm{O}$ and $\mathrm{Pb}(\mathrm{OAc})_{4}{ }^{26}$ Yields were generally moderate and the high toxicity of lead compounds will make this reaction difficult to use in a pharmaceutical setting. The reaction most likely proceeds via fluorination of an aryllead(triacetate) which forms in-situ.

\subsection{Aromatic Radiofluorination}

The introduction of the radioisotope ${ }^{18} \mathrm{~F}$ into drug-like organic molecules is a topic of significant importance in modern organofluorine chemistry. ${ }^{18} \mathrm{~F}$-labelled compounds can be used as imaging agents in positron emission tomography (PET), to diagnose a range of disorders, ranging from cancer, to neurological disorders to heart disease. ${ }^{27}$

${ }^{18} \mathrm{~F}$-labelling presents a particular challenge for the synthetic chemist. The main source of radioactive fluorine is the production of radiofluoride by bombardment of ${ }^{18} \mathrm{OH}_{2}$ with protons in a cyclotron. ${ }^{18} \mathrm{~F}$ is therefore mainly produced as nucleophilic ${ }^{18} \mathrm{~F}$, however the chemistry of nucleophilic fluoride is less well developed than its electrophilic counterparts. As an extra challenge, radiofluoride must be used in concentrations much lower than in traditional fluorination protocols to minimize hazards. In addition, the short half-life of ${ }^{18} \mathrm{~F}(110$ mins) provides a timescale for synthesis which is incompatible with the majority of fluorination strategies. ${ }^{18} \mathrm{~F}$ must therefore be introduced into an imaging molecule at a late stage in its synthesis. Fluorination protocols which transform a stable functional handle into ${ }^{18} \mathrm{~F}$ are therefore urgently required to achieve successful radiofluorination.

Organoboron compounds are an example of such a stable functional handle which can be carried through a synthetic route, before radiofluorination as a final step. Perrin has written a useful review covering radiofluorination of trifluoroborates and application in biological imaging. ${ }^{28}$ In this section we will discuss strategies which have emerged for the radiofluorination of organoboron compounds, with a particular focus on synthetic and mechanistic aspects of this transformation.

\subsubsection{Conversion to iodonium salts}

One of the traditional approaches towards radiofluorination has been through the fluorination of aromatic iodonium salts, which can be formed through the reaction of an oxidized iodine species with an arylboronic acid. Although not a direct fluorination of a $\mathrm{C}-\mathrm{B}$ bond, this strategy will be briefly discussed here.

An attractive recent protocol in this area has been developed by Sanford and Scott, who prepared aryl-mesityl iodonium salts by reaction of arylboronic acids with iodo(mesitylene)diacetate (Scheme 7). ${ }^{29}$ These aryl-mesityl iodonium salts then underwent successful radiofluorination with ${ }^{18} \mathrm{~F}^{-}$in the presence of $(\mathrm{MeCN})_{4} \mathrm{CuOTf}$. Fluorination occurred exclusively on the less hindered non-mesityl aromatic ring, regardless of its electronic properties. The Cu-mediator reduced the temperature required for fluorination significantly

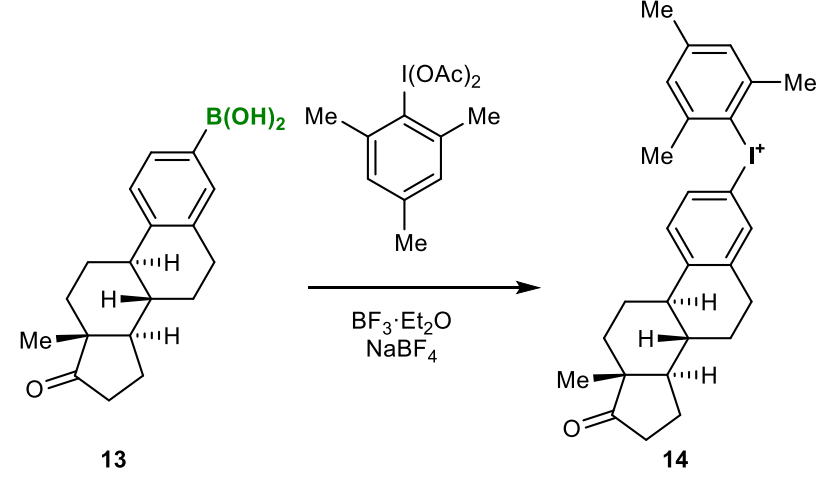

Other Examples<smiles>COc1ccc([18F])cc1OC</smiles>

Radiochemical conversion $51 \pm 6 \%(n=5)$

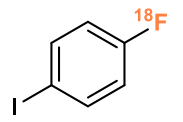

$15 b$

Radiochemical conversion $35 \pm 8 \%(n=3)$

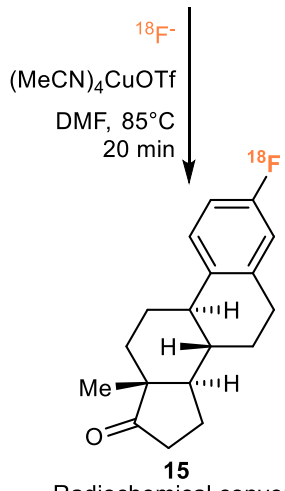

Radiochemical conversion $67 \pm 2 \%(n=3)$

Scheme 7: Cu-mediated fluorination of iodonium salts derived from boronic acids

to around $85{ }^{\circ} \mathrm{C}$. This approach allowed a synthesis of a clinically-relevant estrone-based imaging agent 15.

\subsubsection{Metal-mediated fluorination}

The direct radiofluorination of boronic acid derivatives has seen significant developments in recent years, thanks mainly to the groups of Gouverneur and Ritter. Similarly to fluorination in 'cold' systems, advances in transition-metal mediated radiofluorination have driven this forwards. However, unlike 'cold' systems, requirements are more stringent for radiofluorination, with a particularly significant requirement being that the radiolabel must arise from ${ }^{18} \mathrm{~F}^{-}$, rather than the more commonly used electrophilic sources of fluorine.

Ritter and Hooker showed that Pd(IV)-fluoride complex $\mathbf{1 7}$ (formed by displacing a pyridine ligand from 16 with KF) was able to act as an electrophilic source of fluorine which could fluorinate a palladium(II)-aryl complex 19 (formed by transmetallation of $\mathbf{1 8}$ with a boronic acid) (Scheme 8). ${ }^{30}$ The use of ${ }^{18} \mathrm{~F}^{-}$allowed for the radiolabelling of organic molecules of moderate complexity. However, the requirement for two stoichiometric palladium complexes, whilst acceptable in terms of cost for $\mu \mathrm{mol}$-scale radiochemical work, gives this procedure a level of complexity that is likely to be a barrier to its widespread uptake. The authors were able to later show that this reaction likely proceeds via a single-electron-transfer / fluoride transfer sequence. ${ }^{31}$ The Ritter group have also advanced this work into a sequence which required only a single transition metal complex, and which was mediated by nickel. ${ }^{32}$ However, this procedure used aryl bromides rather than boronic esters to transfer the aryl moiety to the transition metal 

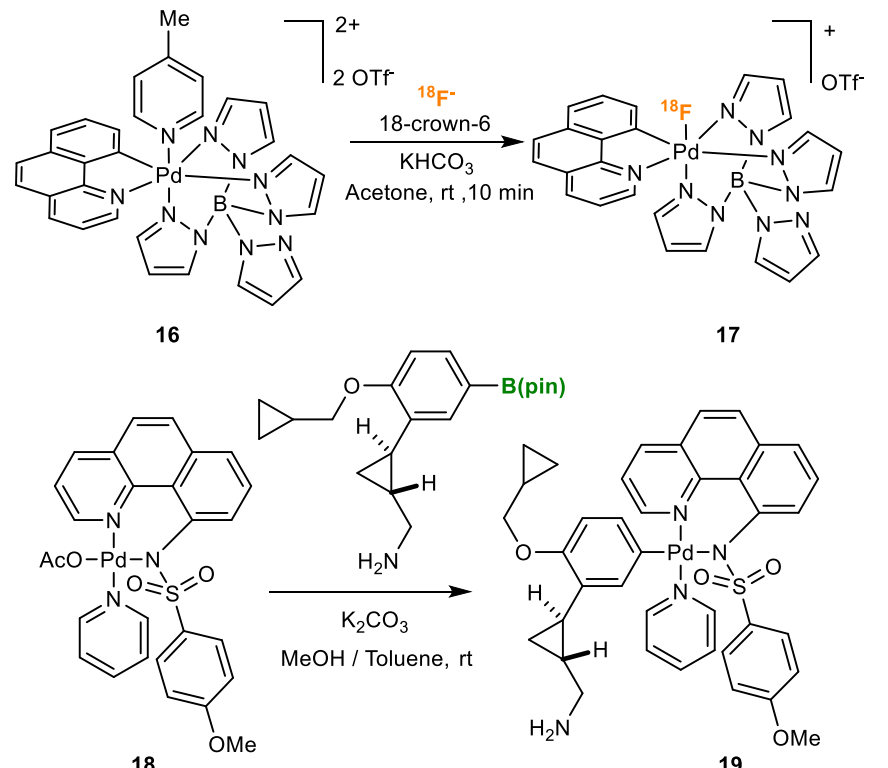

19

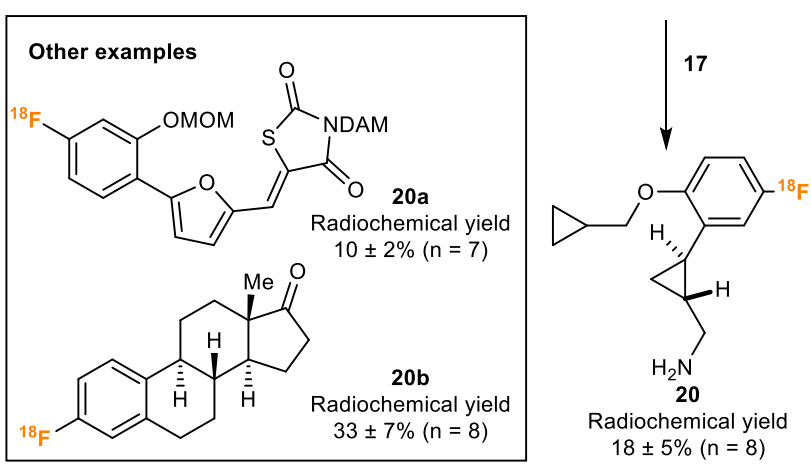

Scheme 8: Pd-mediated radiofluorination of boronic esters

centre and as such shall not be discussed in detail here.

A major advance in the radiofluorination of organoboron compounds was made by Gouverneur in 2014. ${ }^{33}$ Her group showed that $\left[\mathrm{Cu}(\mathrm{OTf})_{2}(\mathrm{py})_{4}\right]$ could catalyse $\mathrm{C}-{ }^{18} \mathrm{~F}$ bond formation from aromatic boronic esters in generally good radiochemical yield and in a short 20 minute timeframe (Scheme 9). This reaction tolerated a broad range of functionality, including amines and heterocycles, and was exemplified by a synthesis of [ ${ }^{18}$ F]FDOPA 21, a method which presented significant advantages over the standard synthesis of this essential radiotracer, not least the replacement of a toxic organostannane precursor with a benign organoboron one. Levels of copper in the final product were shown to be well below that specified by quality control standards. Shortly afterwards, Sanford and Scott reported that a similar procedure could be used for the radiofluorination of arylboronic acids, and demonstrated the utility of this with an efficient synthesis of $\left[{ }^{18} \mathrm{~F}\right]$ FPEB 22, used in the diagnosis of various neurological disorders (Scheme 9). ${ }^{34}$

It was recognized that one disadvantage of late-stage radiofluorination of organoboron compounds could be that significant efforts could be made in the synthesis of a complex organoboron precursor, only for the fluorination to fail in the final step. The Gouverneur group have therefore made significant efforts to understand the scope of this reaction, and

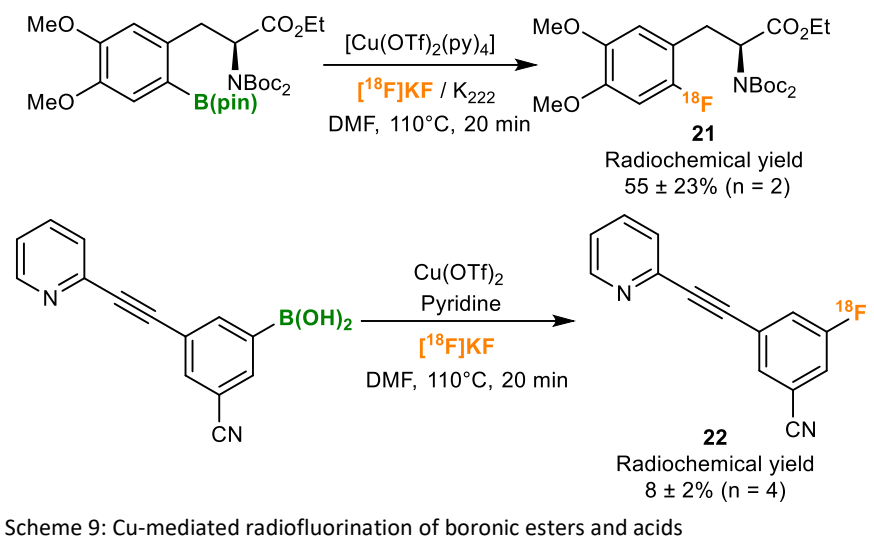

have used a 'Glorius-type robustness screen' 35 to demonstrate a broad range of functional group compatibility, particularly with heterocycles. ${ }^{36}$ Spiking the reaction with a range of compounds containing functional groups of interest showed that $\mathrm{N}$-protection or alkylation of amines was often necessary to achieve good reactivity and that 6-membered nitrogen heteroaromatics were generally tolerated but 5-membered nitrogen heteroaromatics may need protection. Modified conditions with an increased copper loading gave improved<smiles>COc1cc2ncnc(Nc3ccc(F)c(Cl)c3)c2cc1CCCCN1CCOCC1</smiles><smiles></smiles>

$\left[{ }^{18} \mathrm{~F}\right]$ Cabozantinib<smiles>CNc1ccc(-c2nc3ccc(O)cc3s2)cc1[18F]</smiles>

$\left[{ }^{18} \mathrm{~F}\right]$ Flutemetamol<smiles>COc1ccc(OC)c(CN(Cc2ccccc2)c2cc(F)ccc2Oc2ccccc2)c1</smiles>

$\left[{ }^{18} \mathrm{~F}\right] \mathrm{DAA} 1106$<smiles>NC(Cc1c[nH]c2c(F)cccc12)C(=O)O</smiles>

$7-\left[{ }^{18} \mathrm{~F}\right]$ Fluorotryptophan

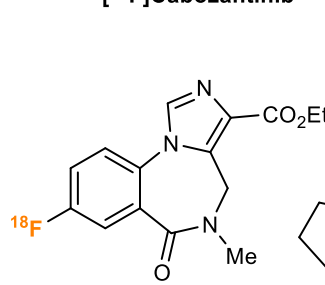

$\left[{ }^{18} \mathrm{~F}\right]$ Flumazenil<smiles>CCOC(=O)c1cnc2ccc(C3CCC[C@H]3c3cccc(F)c3)cn12</smiles>

$\left[{ }^{18}\right.$ F]TRACK

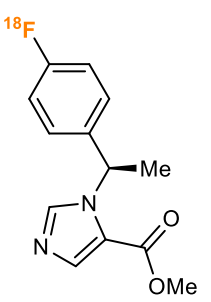

$\left[{ }^{18}\right.$ F]FAMTO
Figure 2: Radiotracer molecules synthesized using Cu-mediated radiofluorination of boronic esters 
results in challenging cases.

This Cu-mediated approach to radiofluorination of organoboronate esters is rapidly emerging as one of the methods of choice for the radiofluorination of aromatic rings. A range of drug-like molecules have been made by the Gouverneur group and others, with some examples of tracer molecules made using this approach highlighted in Figure $2 .{ }^{37}$

\section{Aliphatic Fluorination}

In general, the fluorination of boron-containing aliphatic systems has been less well-studied than aromatic systems. The fluorination of alkenyl boronates, alkyl boronates and boron enolates will be considered in turn.

\subsection{Fluorination of alkenyl boron compounds}

Olah and Prakash have studied the metal-free fluorination of alkenyltrifluoroborates with Selectfluor (Scheme 10). ${ }^{38}$ This proceeded with broader scope and in higher yield than the corresponding metal-free fluorination of aromatic organoboron compounds. ${ }^{15}$ However, even when stereodefined E-alkenyl boronate starting materials were used, a mixture of $Z$ - and $E$ vinyl fluoride products were obtained, often as a 50:50 mixture, as shown for compounds $\mathbf{2 3 a / b}$. If 2 -equivalents of Selectfluor were used then difluoroalcohol products $\mathbf{2 4}$ were obtained in the presence of water, and difluoroamide products $\mathbf{2 5}$ obtained in the presence of a nitrile. These reactions occurred through the intermediacy of a carbocation, through a 'fluoro-Ritter'-like reaction.

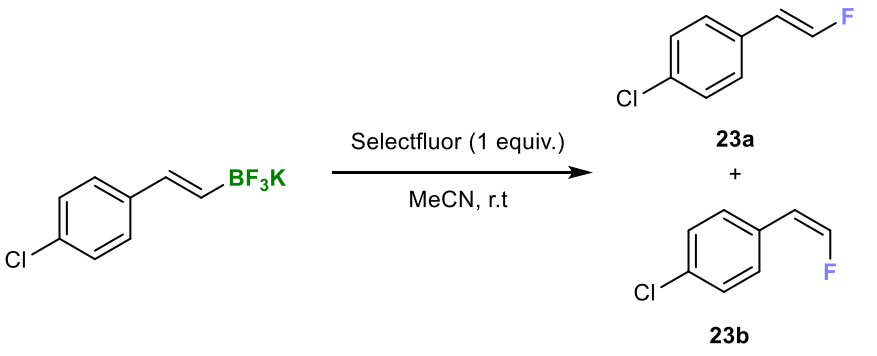

Yield $=78 \%$

$E / Z$ ratio $=50: 50$

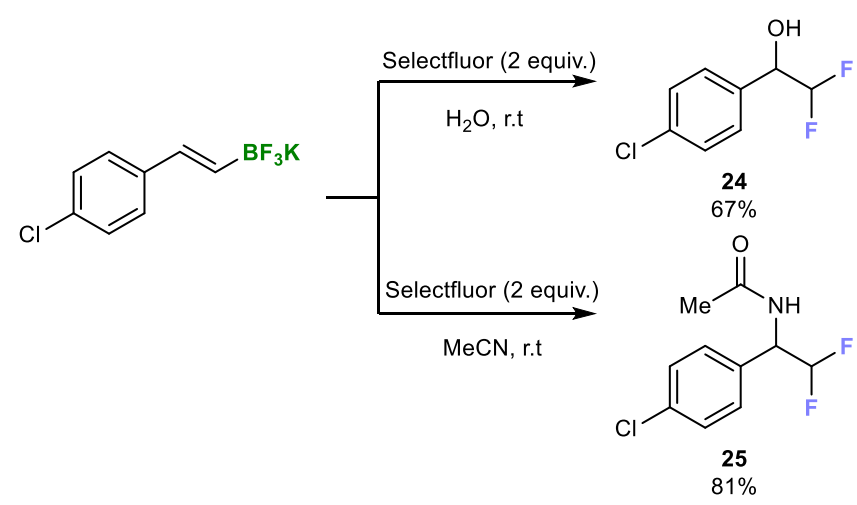

Scheme 10: Metal-free fluorination of alkenyl trifluoroborates

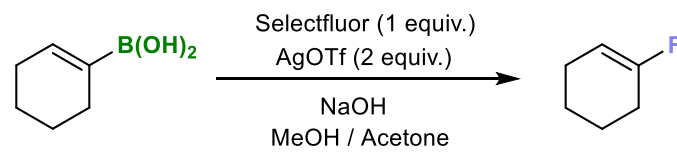

26

$65 \%$

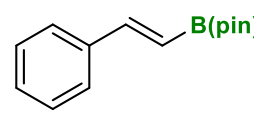

$\underset{\left[\mathrm{Cu}(\mathrm{OTf})_{2}(\mathrm{py})_{4}\right]}{\stackrel{\left[{ }^{18} \mathrm{~F}\right] \mathrm{KF} / \mathrm{K}_{222}}{\longrightarrow}}$
DMF, $110^{\circ} \mathrm{C}, 20 \mathrm{~min}$

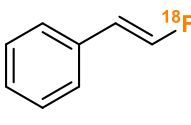

27

Radiochemical yield

$26 \pm 4 \%(n=4)$

Scheme 11: Metal-mediated fluorination of alkenyl organoboron compounds

In comparison, several of the metal-mediated methods developed for aromatic organoboron compound fluorination have also been extended to the fluorination of alkenylboron compounds. For example, Ritter showed that his Ag / Selectfluor mediated method ${ }^{20}$ could also be used to fluorinate alkenylboronic acids, without any of the $E / Z$ isomerization which plagues the metal-free method. ${ }^{38}$ In addition, Gouverneur, as well as Sanford and Scott have shown that $\mathrm{Cu}$ mediated radiofluorination is also an appropriate method for the synthesis of ${ }^{18} \mathrm{~F}$-labelled alkenes, such as $27 .{ }^{33-34}$

\subsection{Fluorination of alkyl boron compounds}

Whilst Lemaire reported a single example of the fluorination of a benzylic secondary alkyl trifluoroborate in 2009,15 it was not until 2014 that a general method for the fluorination of alkyl boron compounds emerged. Chaozhong Li reported the $\mathrm{AgNO}_{3}-$ catalyzed fluorination of alkyl boronic acids and pinacol esters using Selectfluor in aqueous conditions (Scheme 12). ${ }^{39}$ This reaction was applicable to primary, secondary and tertiary alkyl systems. Geminal bis(boron) systems could also be difluorinated to give geminal difluorides $\mathbf{2 8 d}$. The reaction likely proceeds through the formation of alkyl radicals and higher oxidation states of silver. This means that the fluorination is not stereospecific; for example $\mathrm{Yu}$ noted that the Ag-catalyzed fluorination of diastereomerically-pure cyclobutyl-boronate $\mathbf{2 9}$ led to the formation of fluorinated cyclobutanes $30 \mathrm{a} / \mathrm{b}$ as a mixture of diastereoisomers. ${ }^{40}$

Aggarwal has developed a stereospecific fluorination of boron-ate complexes (Scheme 13). ${ }^{41}$ His group have been instrumental in the development of stereospecific transformations of chiral enantiopure organoboron compounds. Enantiopure boron-ate complexes, formed by the reaction of a pinacol boronic ester such as $\mathbf{3 1}$ with phenyllithium, react with Selectfluor II to yield chiral alkyl fluorides with inversion of stereochemistry. Under the optimal conditions, levels of enantiospecificity are generally greater than $90 \%$. It was suggested that this reaction proceeded via a polar $\mathrm{S}_{\mathrm{E}} 2 i n v$ mechanism. Styrene is added as a radical scavenger and the less-oxidizing Selectfluor II used in place of Selectfluor to inhibit single-electron-transfer side reactions, which lead to an erosion of stereochemical purity. If chiral allylic boronates 
<smiles>[R]B1OC(C)(C)C(C)(C)O1</smiles><smiles>O=C(c1ccc(C(F)(F)F)cc1)N1CCC(CF)CC1</smiles><smiles>C[13CH3]</smiles><smiles>O=C(Nc1ccccc1)C1CCC1F</smiles><smiles>O=C(Nc1ccccc1)C1CCC1Br</smiles>

29

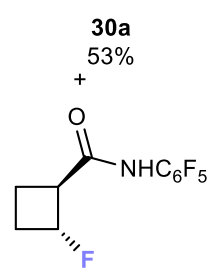

$30 \mathbf{b}$
Scheme 12: Ag-catalyzed fluorination of alkyl pinacolboronates<smiles>CCCCCC(CCc1ccccc1)C(C)C</smiles>

31

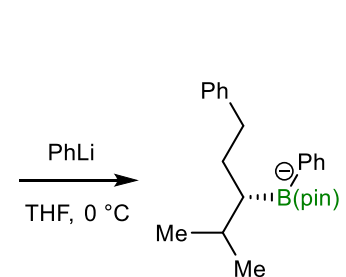

32

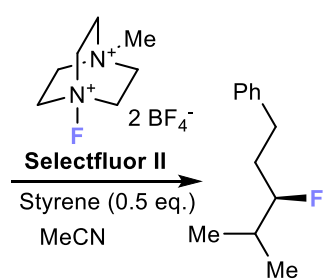

33

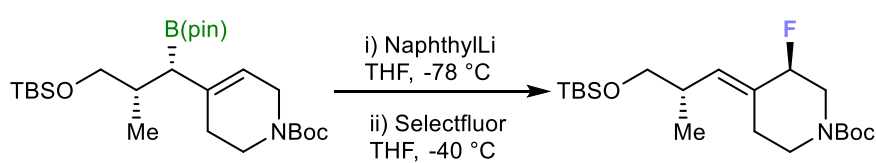

34
Scheme 13: Stereospecific fluorination of boron-ate complexes

such as $\mathbf{3 4}$ are used then fluorination occurs with inversion of stereochemistry and allylic transposition through a polar $\mathrm{S}_{\mathrm{E}} 2^{\prime}$ inv mechanism. ${ }^{42}$ This allowed access to chiral secondary and tertiary allyl fluorides $\mathbf{3 5}$.

\subsection{Fluorination of boron enolates}

Whilst the electrophilic fluorination of enolate derivatives such as silyl enol ethers is well established, the fluorination of boron

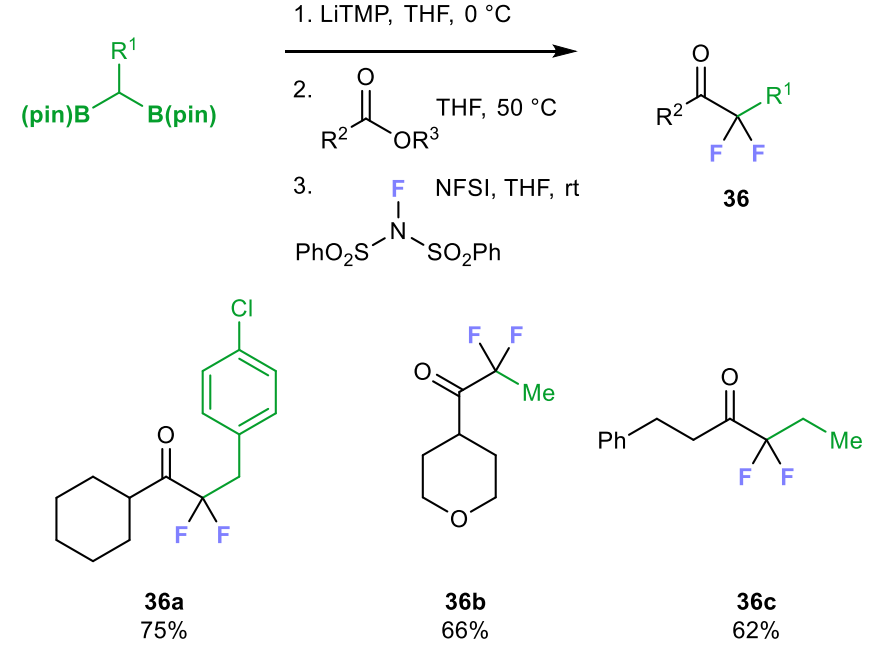

KEY INTERMEDIATE
Oboron) enolate

Scheme 14: Difluorinative coupling of esters and geminal bis(boron) compounds

enolates has been little studied. In 2018 the author's research group reported a novel strategy for the selective synthesis of bis(boron) enolates by the addition of geminal bis(boron) compounds to esters (Scheme 14). ${ }^{43}$ These doubly-nucleophilic intermediates could be trapped by NFSI as an electrophilic source of fluorine to yield a geminally difluorinated ketone. ${ }^{44}$ In cases where enolization was possible on either side of the ketone difluorination occurred selectively at the side where boron was introduced. In addition, no under- or overfluorination was observed. The bis(boron) enolate was observed by NMR and it was suggested that coordination of the alkoxide leaving group from the ester to boron may increase this intermediate's nucleophilicity. Geminal bis(boron) compounds are stable, easily handled precursors which can be deprotonated at their $\alpha$-position by moderately strong, sterically hindered bases such as LiTMP and NaHMDS. ${ }^{45}$

\section{Conclusions}

This short review has covered the methods available for the conversion of $\mathrm{C}-\mathrm{B}$ bonds into $\mathrm{C}-\mathrm{F}$ bonds. The area was only established to any great extent in around 2010, but rapid progress has been made. Copper-mediated methods are emerging as the methods of choice for the fluorination of aromatic organoboron compounds, and have proven to be as appropriate for radiofluorination methods as they are in standard ${ }^{19} \mathrm{~F}$-fluorination. Methods for the fluorination of aliphatic systems are much less well-established than those for aromatic compounds, but Ag-catalyzed radical methods and stereospecific fluorination of boron-ate complexes seem to be of particular utility. 
Many of the protocols developed to date have relied on stoichiometric quantities of transition metal complexes to mediate fluorination, so it will be of great interest to see if more catalytic methods, which use sub-stoichiometric metals, can be developed. Ritter's Pd(III)-catalyzed method ${ }^{19}$ is of interest here and it will be useful to expand this or a similar protocol to aromatic systems bearing electron-withdrawing groups and heterocyclic systems.

In addition, more methods for the stereoselective fluorination of aliphatic organoboron systems would be highly desirable to produce $\mathrm{sp}^{3}$ fluorine-containing systems. An enantioconvergent asymmetric catalytic method that converts racemic organoboron compounds into enantioenriched organofluorine compounds does not currently exist, but would provide a valuable strategy for the synthesis of chiral fluorinated systems.

Developments in radiofluorination have also been rapid. However, no methods currently exist for the radiofluorination of aliphatic organoboron systems, so this is an obvious area for development. A method for the fluorination of organoboron compounds using a nucleophilic fluoride source would be an important first step towards achieving this.

In summary, organoboron compounds are stable and easilyhandled synthetic precursors which are able to undergo fluorination, often mediated using transition metal compounds based on palladium, silver and copper. It will be of great interest to observe how the synthetic methods developed for fluorination and radiofluorination of organoboron systems can drive discovery and diagnosis of a range of medical disorders and treatments, as well as in other applications across the biological, materials and chemical sciences.

\section{Conflicts of interest}

There are no conflicts to declare

\section{Acknowledgements}

The author would like to thank the University of Brighton for start-up funding.

\section{Notes and references}

1.

(a) S. Purser, P. R. Moore, S. Swallow and V. Gouverneur Chem. Soc. Rev., 2008, 37, 320-330; (b) E. P. Gillis, K. J. Eastman, M. D. Hill, D. J. Donnelly and N. A. Meanwell, J. Med. Chem., 2015, 58, 8315-8359.

$2 . \quad$ D. O'Hagan, Chem. Soc. Rev., 2008, 37, 308-319.

3. J. W. B. Fyfe and A. J. B. Watson, Chem, 2017, 3, 31-55.

4. (a) in Boronic Acids, DOI: 10.1002/9783527639328.ch6; (b) C. C. C. Johansson Seechurn, M. O. Kitching, T. J. Colacot and V. Snieckus, Angew. Chem. Int. Ed., 2012, 51, 50625085; (c) A. Biffis, P. Centomo, A. Del Zotto and M. Zecca, Chem. Rev., 2018, 118, 2249-2295.

5. (a) T. Hayashi and K. Yamasaki, Chem. Rev., 2003, 103, 2829-2844; (b) R. Shintani, W.-L. Duan and T. Hayashi, J. Am. Chem. Soc., 2006, 128, 5628-5629; (c) G. Pattison, G.
Piraux and H. W. Lam, J. Am. Chem. Soc., 2010, 132, 1437314375; (d) R. Shintani, M. Takeda, T. Nishimura and T. Hayashi, Angew. Chem. Int. Ed., 2010, 49, 3969-3971; (e) P. Tian, H.-Q. Dong and G.-Q. Lin, ACS Catal., 2012, 2, 95-119; (f) L. Zhang, Z. Qureshi, L. Sonaglia and M. Lautens, Angew. Chem. Int. Ed., 2014, 53, 13850-13853.

6. (a) S. P. Thomas, R. M. French, V. Jheengut and V. K. Aggarwal, Chem. Rec., 2009, 9, 24-39; (b) D. Leonori and V. K. Aggarwal, Acc. Chem. Res., 2014, 47, 3174-3183.

7. (a) C. M. Crudden and D. Edwards, Eur. J. Org. Chem., 2003, 2003, 4695-4712; (b) J. V. Obligacion and P. J. Chirik, Nat. Rev. Chem., 2018, 2, 15-34.

8. (a) V. V. Grushin, Acc. Chem. Res., 2010, 43, 160-171; (b) P. S. Fier and J. F. Hartwig, J. Am. Chem. Soc., 2012, 134, 10795-10798; (c) H. G. Lee, P. J. Milner and S. L. Buchwald, J. Am. Chem. Soc., 2014, 136, 3792-3795; (d) X. Mu, H. Zhang, P. Chen and G. Liu, Chem. Sci., 2014, 5, 275-280.

9. (a) A. Lin, C. B. Huehls and J. Yang, Org. Chem. Front., 2014, 1, 434-438; (b) Q. Cheng and T. Ritter, Trends Chem., 2019, DOI: 10.1016/j.trechm.2019.04.001; (c) V. Gouverneur, R. Szpera, D. F. J. Moseley, L. B. Smith and A. J. Sterling, Angew. Chem. Int. Ed., 2019, DOI: 10.1002/anie.201814457.

10. L. J. Diorazio, D. A. Widdowson and J. M. Clough, Tetrahedron, 1992, 48, 8073-8088.

11. N. S. Zefirov, in Encyclopedia of Reagents for Organic Synthesis, 2001, DOI: 10.1002/047084289X.rc051.

12. I. Vints, J. Gatenyo and S. Rozen, J. Org. Chem., 2013, 78, 11794 - 11797.

13. G. Berionni, V. Morozova, M. Heininger, P. Mayer, P. Knochel and H. Mayr, J. Am. Chem. Soc., 2013, 135, 63176324.

14. S. Rozen and T. Hu, in Encyclopedia of Reagents for Organic Synthesis, 2009, DOI: 10.1002/047084289X.ra029.pub2.

15. C. Cazorla, E. Métay, B. Andrioletti and M. Lemaire, Tetrahedron Lett., 2009, 50, 3936 - 3938.

16. (a) K. L. Hull, W. Q. Anani and M. S. Sanford, J. Am. Chem. Soc., 2006, 128, 7134-7135; (b) K. B. McMurtrey, J. M. Racowski and M. S. Sanford, Org. Lett., 2012, 14, 40944097.

17. T. Furuya, H. M. Kaiser and T. Ritter, Angew. Chem. Int. Ed., 2008, 47, 5993 - 5996.

18. (a) N. D. Ball and M. S. Sanford, J. Am. Chem. Soc., 2009, 131, 3796-3797; (b) T. Furuya, D. Benitez, E. Tkatchouk, A. E. Strom, P. Tang, W. A. Goddard and T. Ritter, J. Am. Chem. Soc., 2010, 132, 3793-3807; (c) M. H. Pérez-Temprano, J. M. Racowski, J. W. Kampf and M. S. Sanford, J. Am. Chem. Soc., 2014, 136, 4097-4100.

19. A. R. Mazzotti, M. G. Campbell, P. Tang, J. M. Murphy and T. Ritter, J. Am. Chem. Soc., 2013, 135, 14012 - 14015.

T. Furuya and T. Ritter, Org. Lett., 2009, 11, 2860 - 2863.

21. T. Furuya, A. E. Strom and T. Ritter, J. Am. Chem. Soc., 2009 131, 1662-1663.

22. P. S. Fier, J. Luo and J. F. Hartwig, J. Am. Chem. Soc., 2013, 135, 2552 - 2559.

23. Y. Ye and M. S. Sanford, J. Am. Chem. Soc., 2013, 135, 4648 $-4651$.

24. Y. Ye, S. D. Schimler, P. S. Hanley and M. S. Sanford, J. Am. Chem. Soc., 2013, 135, 16292 - 16295.

S. R. Dubbaka, S. Gadde and V. R. Narreddula, Synthesis, 2015, 47, 854 - 860. 
26.

G. V. D. Meio and J. T. Pinhey, Chem. Commun., 1990, 1065 - 1066.

27. (a) S. Preshlock, M. Tredwell and V. Gouverneur, Chem. Rev., 2016, 116, 719-766; (b) X. Deng, J. Rong, L. Wang, N. Vasdev, L. Zhang, L. Josephson and S. H. Liang, Angew. Chem. Int. Ed., 2019, 58, 2580-2605.

28. D. M. Perrin, Curr. Opin. Chem. Biol., 2018, 45, 86-94.

29. N. Ichiishi, A. F. Brooks, J. J. Topczewski, M. E. Rodnick, M. S. Sanford and P. J. H. Scott, Org. Lett., 2014, 16, 3224 3227.

30. E. Lee, A. S. Kamlet, D. C. Powers, C. N. Neumann, G. B. Boursalian, T. Furuya, D. C. Choi, J. M. Hooker and T. Ritter, Science, 2011, 334, 639.

31. J. R. Brandt, E. Lee, G. B. Boursalian and T. Ritter, Chem. Sci., 2013, 5, 169 - 179.

32. E. Lee, J. M. Hooker and T. Ritter, J. Am. Chem. Soc., 2012, 134, $17456-17458$.

33. M. Tredwell, S. M. Preshlock, N. J. Taylor, S. Gruber, M. Huiban, J. Passchier, J. Mercier, C. Genicot and V. Gouverneur, Angew. Chem. Int. Ed., 2014, 53, 7751 - 7755.

34. A. V. Mossine, A. F. Brooks, K. J. Makaravage, J. M. Miller, N. Ichiishi, M. S. Sanford and P. J. H. Scott, Org. Lett., 2015, 17, 5780 - 5783.

35. K. D. Collins and F. Glorius, Nat. Chem., 2013, 5, 597.

36. N. J. Taylor, E. Emer, S. Preshlock, M. Schedler, M. Tredwell, S. Verhoog, J. Mercier, C. Genicot and V. Gouverneur, J. Am. Chem. Soc., 2017, 139, 8267 - 8276.

37. (a) B. D. Zlatopolskiy, J. Zischler, P. Krapf, F. Zarrad, E. A. Urusova, E. Kordys, H. Endepols and B. Neumaier, Chem. Eur. J., 2015, 21, 5972 - 5979; (b) S. Preshlock, S. Calderwood, S. Verhoog, M. Tredwell, M. Huiban, A. Hienzsch, S. Gruber, T. C. Wilson, N. J. Taylor, T. Cailly, M. Schedler, T. L. Collier, J. Passchier, R. Smits, J. Mollitor, A. Hoepping, M. Mueller, C. Genicot, J. Mercier and V. Gouverneur, Chem. Commun., 2016, 52, 8361 - 8364; (c) Z. Zhang, J. Lau, H.-T. Kuo, C. Zhang, N. Colpo, F. Bénard and K.-S. Lin, Bioorg. Med. Chem. Lett., 2017, 27, 2094 - 2098; (d) V. Bernard-Gauthier, A. V. Mossine, A. Mahringer, A. Aliaga, J. J. Bailey, X. Shao, J. Stauff, J. Arteaga, P. Sherman, M. Grand'Maison, P.-L. Rochon, B. Wängler, C. Wängler, P. Bartenstein, A. Kostikov, D. R. Kaplan, G. Fricker, P. RosaNeto, P. J. H. Scott and R. Schirrmacher, J. Med. Chem., 2018, 61, 1737 - 1743; (e) S. Bongarzone, F. Basagni, T. Sementa, N. Singh, C. Gakpetor, V. Faugeras, J. Bordoloi and A. D. Gee, Nucl. Med. Biol., 2018, 68-69, 14-21; (f) V. T. Lien, J. Klaveness and D. E. Olberg, J. Label. Compd. Radiopharm., 2018, 61, 11 - 17; (g) B. D. Zlatopolskiy, J. Zischler, D. Schäfer, E. A. Urusova, M. Guliyev, O. Bannykh, H. Endepols and B. Neumaier, J. Med. Chem., 2018, 61, 189 - 206.

38. N. A. Petasis, A. K. Yudin, I. A. Zavialov, G. K. S. Prakash and G. A. Olah, Synlett, 1997, 1997, 606-608.

39. Z. Li, Z. Wang, L. Zhu, X. Tan and C. Li, J. Am. Chem. Soc., 2014, 136, 16439-16443.

40. J. He, H. Jiang, R. Takise, R.-Y. Zhu, G. Chen, H.-X. Dai, T. G. M. Dhar, J. Shi, H. Zhang, P. T. W. Cheng and J.-Q. Yu, Angew. Chem. Int. Ed., 2016, 55, 785-789.

41. C. Sandford, R. Rasappan and V. K. Aggarwal, J. Am. Chem. Soc., 2015, 137, 10100-10103.

42. C. Garcia-Ruiz, J. L. Y. Chen, C. Sandford, K. Feeney, P. Lorenzo, G. Berionni, H. Mayr and V. K. Aggarwal, J. Am Chem. Soc., 2017, 139, 15324-15327.
43.

44.

45.
C. E. Iacono, T. C. Stephens, T. S. Rajan and G. Pattison, J. Am. Chem. Soc., 2018, 140, 2036-2040.

(a) L. S. Dobson and G. Pattison, Chem. Commun., 2016, 52, 11116-11119; (b) D. J. Leng, C. M. Black and G. Pattison, Org. Biomol. Chem., 2016, 14, 1531-1535; (c) G. Pattison, Eur. J. Org. Chem., 2018, 2018, 3520-3540.

(a) K. Endo, M. Hirokami and T. Shibata, J. Org. Chem., 2010, 75, 3469-3472; (b) J. R. Coombs, L. Zhang and J. P. Morken, Org. Lett., 2015, 17, 1708-1711; (c) T. C. Stephens and G. Pattison, Org. Lett., 2017, 19, 3498-3501. 